\title{
A Comparative Study between Entropy and Clinical Response to Determine the Requirement of Propofol for Induction of General Anesthesia in Geriatric Patients
}

\author{
MAI A.K. NIDA, M.Sc.; WESAM F. MOUSA, M.D.; AHMED S. ELGEBALY, M.D. and \\ HESHAM E. EL-ASHRY, M.D. \\ The Department Anesthesiology and Surgical Intensive Care, Faculty of Medicine, Tanta University
}

\begin{abstract}
Background: Anesthesia under dosage causes awareness, while over dosage results in drug complications. Endotracheal intubation must be after an adequate level of anesthesia. Propofol is an IV short-acting anesthetic which causes hypotension in a dose dependent effect. With entropy, SE level 4060 and RE-SE difference $<10$ are the target during anesthesia. Geriatrics are different in EEG spectral patterns than young patients and are more vulnerable to complications of endotracheal intubation and propofol.
\end{abstract}

Aim of Study: The aim of this study was to compare between the conventional clinical end-point of hypnosis and entropy on the dosage requirement of propofol and hemodynamic during propofol induction of general anesthesia in geriatric patients.

Methods and Material: 60 patients, aged $60-80 y$, from both sexes, ASA I-II scheduled for an elective surgery required general anesthesia and endotracheal intubation were included. Group-I (control group): Propofol 30mg every $1 \mathrm{~min}$ till loss of response to verbal commands and group-II (entropy group): Propofol $30 \mathrm{mg}$ every $1 \mathrm{~min}$ till response entropy $48 \pm 2$. Patient's demographic data, the total dose of propofol used for induction, (HR, MAP and entropy parameters) at baseline (T1), after induction of anesthesia (T2), during (T3), $1 \mathrm{~min}$ and $5 \mathrm{~min}$ after tracheal intubation (T4, T5).

Results: Total dose of propofol, HR \& MAP readings revealed no significant difference between two groups. After induction, both RE and SE dropped significantly in both groups when compared to baseline. There was no difference in SE \& RE between the two groups.

Conclusion: During intubation, usual titration of propofol until loss of verbal response, with the dose given in our study, is as good as entropy monitoring in elderly patients. So, routine use for this may not be necessary and can be used in other age groups, other anesthesia situations, medicolegal purposes and research.

Correspondence to: Dr. Mai Abd El-Haleem Kamal Nida, The Department Anesthesiology and Surgical Intensive Care, Faculty of Medicine, Tanta University
Key Words: Entropy - Clinical response - Requirement of propofol-Geriatric patients.

\section{Introduction}

ANESTHESIA under dosage causes awareness, while over dosage results in drug complications [1]. Endotracheal intubation must be after an adequate level of anesthesia as light anesthesia leads to sympathetic stimulation, laryngospasm, bronchospasm, and traumatization of airway and over dosage of anesthetics with delay in intubation leads to bradycardia, arrhythmia, hypotension and at last, respiratory and cardiovascular arrest [2]

Propofol is an IV short-acting anesthetic which causes hypotension in a dose dependent effect [3] Over or under dosage may occur if fixed dose is given guided by loss of verbal response [1]

Entropy monitor is a combined EEG and EMG monitor which is used to monitor hypnosis and depth of anesthesia [4]. The State Entropy (SE) reflects the effect of anesthetics on the cortex as it is the EEG dominant part whereas the Response Entropy (RE) comprises both EEG and frontal EMG [5], so it impends awakening of the patient. RE varies from 0 to 100 , whereas SE ranges between 0 and 91 . SE level 40-60 and RE-SE difference $<10$ are the target during anesthesia $[6,7]$.

Geriatrics are different in EEG spectral patterns than young patients and also they are more vulnerable to complications of endotracheal intubation and propofol $[\mathbf{8 , 9}]$.

The aim of this study was to compare between the conventional clinical end-point of hypnosis and entropy on the dosage requirement of propofol 
and hemodynamic during propofol induction of general anesthesia in geriatric patients.

\section{Methods and Material}

This prospective randomized blind study was carried out at Tanta University Hospitals for six months from October 2017 to March 2018. All data of patients was confidential with secret codes and private file for each patient. After approval from ethical committee, a written informed consent obtained from all participants in this research. Each patient received an explanation to the purpose of the study.

Sixty patients, aged $60-80 \mathrm{y}$, from both sexes, ASA I-II scheduled for an elective surgery required general anesthesia and endotracheal intubation were included.

Exclusion criteria were: Patient refusal, patients with severe cardiac disease, liver diseases and renal dysfunction, patients with known hypersensitivity to study drugs, anticipated difficult airway access, two unsuccessful attempts of tracheal intubation were considered secondary exclusion criterion, history of alcohol or drug abuse and chronic analgesic use, patients with history of any psychiatric illness, stroke with residual neurologic deficits or altered mentation, CNS disorders, Alzheimer disease, dementia, brain atrophy and other neurological disorders and patients under treatment with sedatives, anticonvulsants, opioids or any longterm use of other drugs affecting the CNS. This study included 60 patients who were randomly classified using sealed envelopes into two equal groups, each group contains 30 patients.

Pre-operative assessment was done by: History taking, clinical examination including airway evaluation using Mallampati classification, routine laboratory investigations including complete blood picture, coagulation profile (prothrombin time, activity and INR), liver functions, renal functions, random blood sugar, cardiovascular assessment and ECG. A pre-operative fasting period of 6 hours for solids and 2 hours for clear fluids. No premeditation was given.

On arrival of the patient to OR, an IV line inserted and IV infusion of ringer lactated was started. All patients connected to monitor displaying the following: Electrocardiogram (ECG), Heart Rate (HR), peripheral oxygen saturation ( $\mathrm{SpO} 2)$ using pulse oximetry, Non-Invasive Blood Pressure (NIBP) monitoring Mean Arterial blood Pressure (MAP), end tidal carbon dioxide (EtCO 2) by using capnogram, entropy parameters (SE \& RE) by GE
Datex-Ohmeda EntropyTM Module. By applying the entropy sensor (self-adhesive entropy sensor consisting of three electrodes) on the patient's forehead (fronto-temporal region) according to the instructions provided on the sensor pouch after skin preparation with disinfectant alcohol and slight rubbing. This sensor connected to the entropy monitor (M-Entropy Plug-in Module S/5; DatexOhmeda, Finland). Baseline parameters were recorded.

Before induction of anesthesia, $100 \%$ oxygen for 2-3min was applied. The induction was done with IV fentanyl (1 $\mathrm{g} / \mathrm{k}$ ), followed $3 \mathrm{~min}$ later by propofol as following: Group-I (control group): IV propofol 30mg was given every 1 minute till loss of response to verbal commands. Group-II (entropy group): IV propofol 30mg every 1 minute till response entropy $48 \pm 2$ as an end point of hypnosis. Then cis-atracurium $0.15 \mathrm{mg} / \mathrm{kg}$ was given then lungs were ventilated with bain circuit by oxygen and isoflurane at $1 \mathrm{MAC}$ for 3 minutes by tightly fitted face mask, thereafter, tracheal intubation was performed with a cuffed endotracheal tube of appropriate size. Tidal volume and respiratory rate were adjusted to maintain $\mathrm{EtCO} 2$ between 32 to $35 \mathrm{mmHg}$. Maintenance was by mixture of oxygen and isoflurane at 1MAC.

The following data were measured for each patient: Patient's demographic data (age, sex, weight and body mass index), the total dose of propofol used for induction of anesthesia to attain the desired end points as loss of verbal response (Group I) or response entropy of $48 \pm 2$ (Group II) were recorded (primary outcome), hemodynamics (HR \& MAP) were recorded at baseline, induction, intubation, and at 1,5 minutes after intubation and entropy parameters (RE and SE). The values of entropy and hemodynamics were recorded at the following measurement time (T): Baseline value before induction of anesthesia $\left(\mathrm{T}_{1}\right)$, after induction of anesthesia at end point of hypnosis as per group $\left(\mathrm{T}_{2}\right)$, during tracheal intubation $\left(\mathrm{T}_{3}\right), 1$ minute after tracheal intubation $\left(\mathrm{T}_{4}\right)$ and 5 minutes after tracheal intubation $\left(\mathrm{T}_{5}\right)$.

Intraoperative hypotension was defined as a fall in MAP by $>20 \%$ from baseline and was treated with boluses of ephedrine $6 \mathrm{mg}$ every $3 \mathrm{~min}$ as needed. Bradycardia was defined as HR $<50$ beats/ min and was treated with atropine $0.01 \mathrm{mg} / \mathrm{kg}$ in both groups. After our study measurements completed, the study was discontinued.

The sample size was calculated according to the results of a previous study [10] using epi-info 
software computer program created by center of disease prevention and control, version 2002. It was calculated as 30 patients for each study group based on the following criteria: $95 \%$ confidence limit, $80 \%$ power of study, group I to Group II ratio 1: 1 and 2 groups comparison (30 in each).

The collected data were organized, tabulated and statistically analyzed using SPSS (IBM, USA) software statistical computer package Version 25. For quantitative data, the range, mean and standard deviation were calculated. For qualitative data, comparison between two groups was done using Chi-square test $\left(\chi^{2}\right)$. For comparison between means of parametric data, student $t$-test was used. The level of significance was adapted at $p$-value $<0.05$.

\section{Results}

In this study, 69 patients were assessed for eligibility; 7 patients did not meet the inclusion criteria and 2 patients refused to participate in the study. 60 patients were randomized into two groups 30 patients in each one; Group-I control group and Group-II entropy group. All patients are followedup and analyzed Fig. (1).

There was no significant difference between both groups as regard demographic data (age, weight and sex) (Table 1). Comparison of HR \& MAP among the studied groups revealed insignificant difference. In both groups, the HR was significantly decrease from the baseline with induction but increased insignificantly at intubation Fig. (2). MAP significantly decreased after induction compared to the baseline in both groups Fig. (3).

There was no significant difference in the entropy readings (RE \& SE) at baseline, induction, intubation, $1 \mathrm{~min}$ and 5 minutes after intubation between the two groups after induction, both RE and SE dropped significantly in both groups when compared to baseline (Tables 2,3). Comparison of total dose of propofol used for induction of anesthesia between two groups revealed that there was no significant difference.

Table (1): Patients' demographic data and dosage of propofol in the two studied groups.

\begin{tabular}{|c|c|c|c|}
\hline & $\begin{array}{c}\text { Group I } \\
(\mathrm{n}=30)\end{array}$ & $\begin{array}{c}\text { Group II } \\
(\mathrm{n}=30)\end{array}$ & $\begin{array}{c}p- \\
\text { value }\end{array}$ \\
\hline \multicolumn{4}{|l|}{ Age (years): } \\
\hline Range & $62-80$ & $60-80$ & \multirow[t]{2}{*}{0.307} \\
\hline Mean \pm SD & $73.03 \pm 6.12$ & $71.4 \pm 6.16$ & \\
\hline \multicolumn{4}{|l|}{ Weight $(K g)$ : } \\
\hline Range & $56-85$ & $55-85$ & \multirow[t]{2}{*}{0.241} \\
\hline Mean \pm SD & $71.27 \pm 8.85$ & $68.57 \pm 8.79$ & \\
\hline \multicolumn{4}{|l|}{ BMI: } \\
\hline Range & $22-33$ & $21-32$ & \multirow[t]{2}{*}{0.390} \\
\hline Mean \pm SD & $26.4 \pm 2.74$ & $25.8 \pm 2.63$ & \\
\hline \multicolumn{4}{|l|}{ Sex: } \\
\hline Male $\quad \mathrm{N}(\%)$ & $15(50 \%)$ & $17(56.7 \%)$ & \multirow[t]{2}{*}{0.796} \\
\hline Female N $(\%)$ & $15(50 \%)$ & $13(43.3 \%)$ & \\
\hline \multicolumn{4}{|c|}{ Dosage of propofol $(\mathrm{mg})$ : } \\
\hline Range & $60-130$ & $55-110$ & \multirow[t]{2}{*}{0.0852} \\
\hline Mean \pm SD & $91.27 \pm 17.90$ & $83.83 \pm 14.84$ & \\
\hline
\end{tabular}

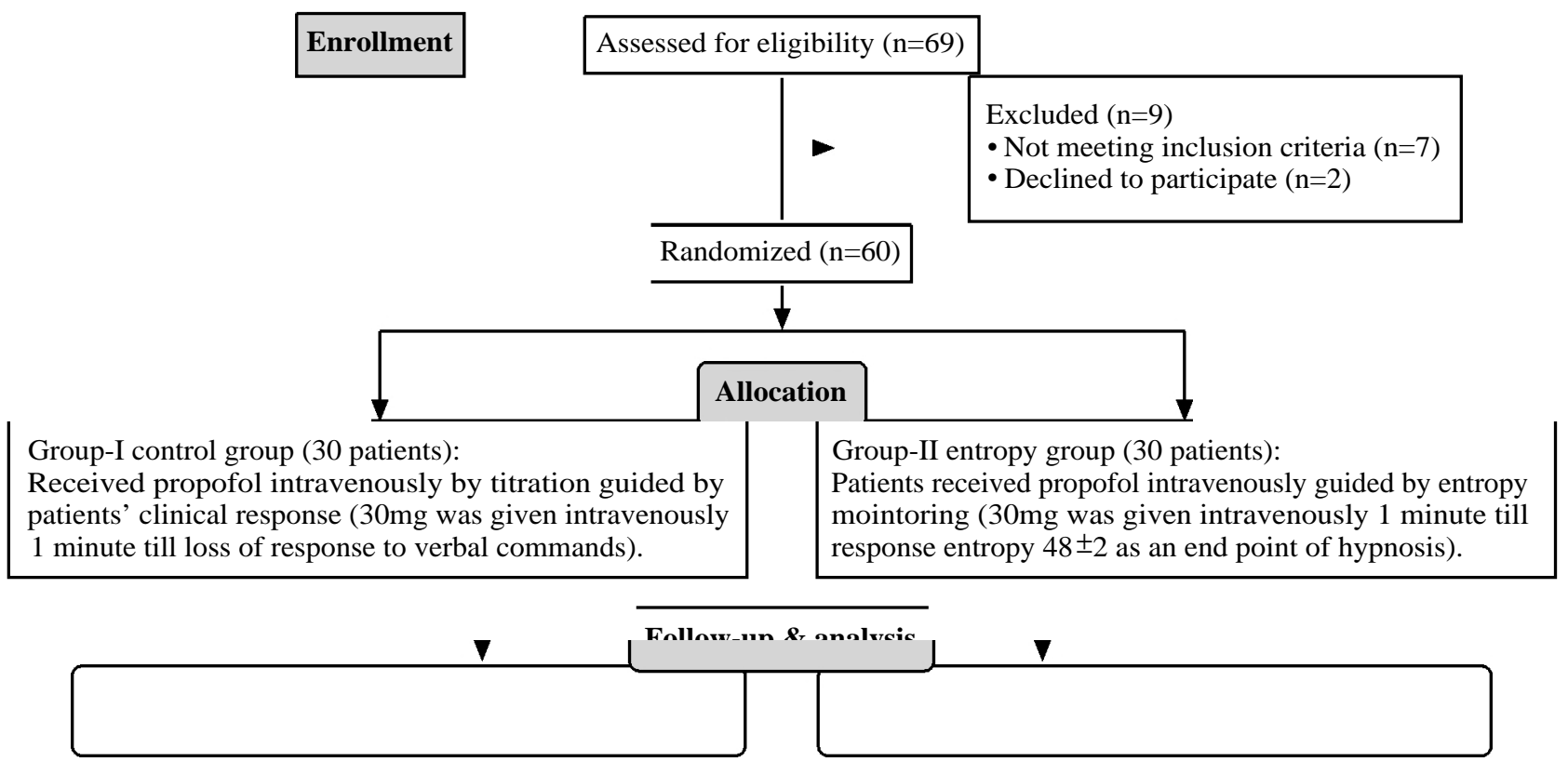

Fig. (1): Patient flowchart summarizing enrollment, allocation, follow-up and analysis in the study protocol. 
Table (2): Comparison of RE between the two groups.

Table (3): Comparison of SE between the two groups.

\begin{tabular}{|c|c|c|c|c|c|c|c|c|c|c|c|}
\hline & $\mathrm{T} 1$ & $\mathrm{~T} 2$ & $\mathrm{~T} 3$ & $\mathrm{~T} 4$ & $\mathrm{~T} 5$ & & $\mathrm{~T} 1$ & $\mathrm{~T} 2$ & $\mathrm{~T} 3$ & $\mathrm{~T} 4$ & $\mathrm{~T} 5$ \\
\hline Group I: & & & & & & Group I: & & & & & \\
\hline Mean & 96.17 & 46.37 & 54.2 & 52.9 & 49.1 & Mean & 87.33 & 44.2 & 51.67 & 50.4 & 47.17 \\
\hline SD & 1.89 & 4.15 & 4.44 & 4.4 & 4.39 & SD & 2.02 & 4.01 & 4.49 & 4.51 & 4.32 \\
\hline Group II: & & & & & & Group II: & & & & & \\
\hline Mean & 97.06 & 47.73 & 55.73 & 54.53 & 50.33 & Mean & 87.73 & 45.7 & 53.27 & 52.17 & 48.17 \\
\hline $\mathrm{SD}$ & 1.7 & 1.59 & 2.46 & 2.39 & 2.64 & $\mathrm{SD}$ & 1.74 & 2 & 2.76 & 2.73 & 2.82 \\
\hline$p$-value & 0.058 & 0.097 & 0.104 & 0.079 & 0.193 & $p$-value & 0.41 & 0.072 & 0.102 & 0.071 & 0.29 \\
\hline
\end{tabular}

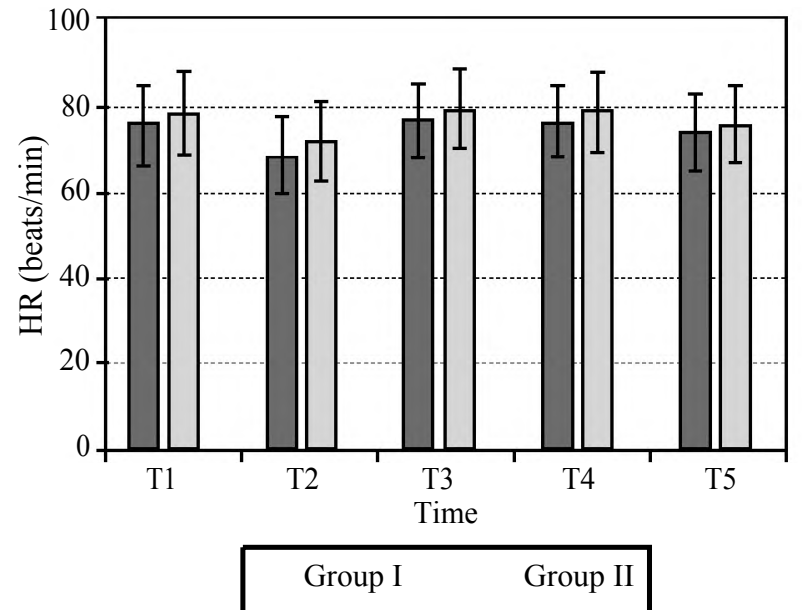

Fig. (2): Comparison between heart rate changes in both groups.

\section{Discussion}

With advancing of age, many physiological, pharmacokinetic \& pharmacodynamic alterations exist. Therefore, geriatrics may benefit from monitoring of depth of anesthesia to titrate induction agents [11]

The present study showed that use of entropy was associated with insignificant reduction in dosage of propofol used for induction. In agreement with our study, Arya et al., [10] who showed no significant difference when assessed clinically or by BIS monitoring (the end point was continuous BIS value of $48 \pm 2$ for $1 \mathrm{~min}$ ). Also, Rundshagen et al., [12] who observed that there was no significant difference in total propofol or remifentanil dose between EEG group (adjusted to a Narcotrend level of D2-E0) and the other group (guided by clinical manifestations).

On the contrary to our results, Riad W et al., [13] who demonstrated that the induction dose of propofol was significantly decreased with adequate cardiovascular stability using EEG entropy (to keep SE 50 \& SB-RE difference $<10$ ) than control group (induction by $1.75 \mathrm{mg} / \mathrm{kg}$ propofol). The difference with our results could be explained by

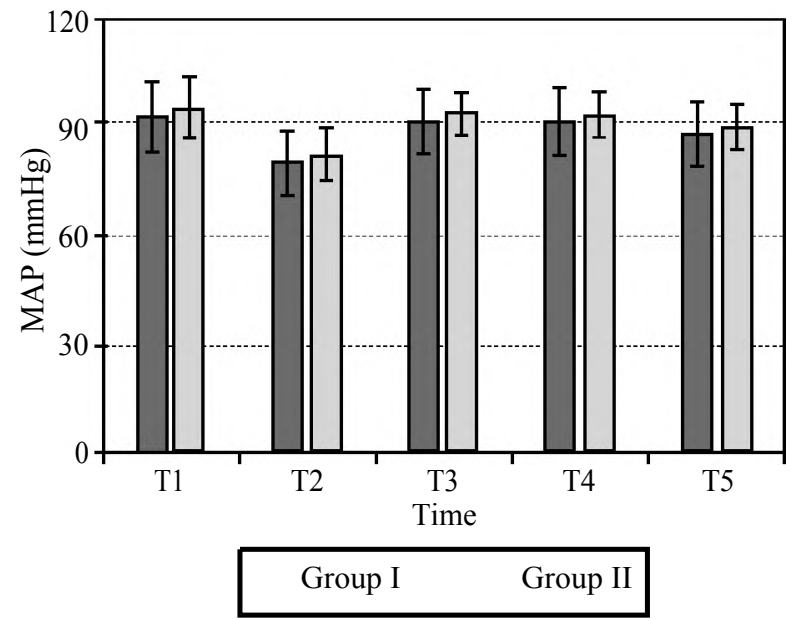

Fig. (3): Comparison of MAP changes between Group I \& Group II.

the control group was given a higher dose of propofol $(1.75 \mathrm{mg} / \mathrm{kg})$.

Also, Rao et al., [14] studied two groups: Control group (propofol till loss of response to verbal commands) and study group (propofol until the SE was $<50$ and SE-RE difference was $<10$ ). In the study group, extra dose of propofol $(30 \mathrm{mg} / 30 \mathrm{~s})$ was given to achieve entropy target and no extra dose of propofol was given in the control group. This study found that there was no difference between control group and study group in dose of propofol $/ \mathrm{kg}(1.80 \pm 0.23 \mathrm{mg} / \mathrm{kg}$ vs $1.78 \pm 0.25 \mathrm{mg} / \mathrm{kg}$ respectively). However, the total dose was higher in the study group more than control group (1.98 $\pm 0.217 \mathrm{mg} / \mathrm{kg}$ Vs $1.80 \pm 0.23 \mathrm{mg} / \mathrm{kg}$ respectively) as $78 \%$ patients needed an extra dose of propofol. The difference with our results could be explained by the following differences in the study methodology: (I) Maintenance of SE $<50$ until completion of endotracheal intubation, (Ii) Inclusion of younger patients (age: 18-58y) (Iii) Rocuronium (the muscle relaxant used in the study) injection pain.

Moreover, Gruenewald et al., [15] used propofol and remifentanil for total IV anesthesia and found that total propofol dose (induction \& maintenance) was lower the entropy group (with a target SE 
range of 40-60) than in the standard practice group and in contrast, the total remifentanil dose was higher. This may be attributed to the decreased usage during maintenance and not during induction. Also, in disagreement with our results, Vakkuri A et al., [16] who concluded that usage of entropy is associated with decreased propofol dose during anesthesia and early recovery than anesthesia guided by clinical manifestations of inadequate anesthesia and hemodynamics. The difference with our results could be explained by wide range of age of patients (18-80) years old.

Also, Gürses et al., [17] studied three groups. Group I: Propofol $2 \mathrm{mg} / \mathrm{kg}$ was given to for induction. Groups II and III: Propofol was given untill no response to verbal commands and until BIS level were around 50 respectively. This study found that the induction dose of propofol assessed by BIS results in a significant decrease in propofol amount without complications (36\% and $43 \%$ in Groups II and III respectively as compared with Group I). The difference with our study could be explained by different age (28-55 years) and high dose given in Group I ( $2 \mathrm{mg} / \mathrm{kg})$. Moreover, Lee JY et al., [18] study which was done on 70 children, aged 3-10 and they concluded that entropy (SE was maintained at 40-60) was associated with decreased propofol dose and more rapid recovery compared to standard practice (HR and SBP were maintained at $20 \%$ of baseline). The difference with our results as our study cases are elderly who are more vulnerable to the anesthetic effects of propofol. Schultz et al., [9] found that with the same dose of propofol, lower values of EEG in geriatrics than young patients.

As regard the hemodynamics, there were no significant changes in HR and MAP in between both groups. In both groups, the HR was significantly decreased from the baseline with induction but insignificantly increased at intubation. There is insignificant change in HR 1 minute after intubation and significant decrease after 5 minutes of intubation in both groups when compared to baseline. In agreement with our study, Arya et al., [10] Riad et al., [12], Gürses et al., [17] and Gruenewald et al., [15] who showed that HR values did not significantly differ between the two groups.

On the contrary, Rao et al., [14], found that the HR was significantly lower in the entropy group at $1 \mathrm{~min}$ after intubation but there was no significant difference in the HR at baseline, induction, intubation in both groups. The difference with our results could be explained by maintenance of SE $<50$ until intubation was done.
As regard MAP, there was no significant difference at all readings between the groups. However, after induction, the MAP significantly decreased compared to the baseline in both groups. There was a significant decrease in MAP after induction of anesthesia and significant decrease in MAP after 5 minutes after intubation when compared to the baseline values. There were no significant changes in MAP after intubation and 1 minute after intubation when compared to the baseline values.

In correspondence with our results, Vakkuri A et al., [16]. In the entropy group, the rate of propofol was adjusted to keep SE between 45-65 until the last $15 \mathrm{~min}$ of anesthesia and rate of alfentanil to control SE-RE difference $<10$ and HR \& MAP within $\pm 20 \%$ of baseline. In the control groups, propofol and alfentanil were given to maintain HR \& MAP within $\pm 20 \%$ of baseline. This study showed that HR \& MAP were comparable between groups. This is explained by that alfentanil dose was guided by HR \& MAP in the two groups, not only in the control group. Also, Arya et al., [10] and Gruenewald et al., [15] found that the changes in MAP values did not differ between the two groups. Also, Rao et al., [14] demonstrated that there was no difference in the MAP between the groups at baseline, induction, intubation and $1 \mathrm{~min}$ after intubation. However, SBP and DBP after induction decreased compared to baseline in both groups.

On the contrary to our results, Riad W et al., [13] who demonstrated that SBP, DBP and MAPs were decreased in both groups after anesthesia induction, but the hypotension was significantly greater in the control group (this may be due to larger induction dose in the control group (1.75 $\mathrm{mg} / \mathrm{kg}$ ). It also found that SBP, DBP and MAP were not different before induction and after intubation between both groups. Also, in contrast with our results, Gürses et al., [17], conducted their study on 60 patients undergoing surgery during GA who were randomly classified into three groups according to the propofol dose at the induction and found that SBP was lower in Group I than the other groups after anesthesia induction, this may be due to larger induction dose $(2 \mathrm{mg} / \mathrm{kg})$. It also found SBP values did not change after anesthesia induction in Groups II and III. DBP were not different before and after anesthesia induction.

As regard the changes in the entropy parameter, the present study showed that there was no difference in the entropy readings (RE \& SE) between the two groups. After induction, both RE and SE 
dropped significantly in both groups when compared to baseline. Stress response associated with intubation lead to a significant increase of RE and SE in both control and entropy groups, but the RE and SE values remained within the anesthetic window (40-60).

In agreement with our results, Gruenewald et al., [15] found that SE \& RE decreased after induction of anesthesia and increased during emergence and there was no significant difference with control and entropy groups.

In disagreement with our results, Riad $\mathrm{W}$ et al., [13] who concluded that there was a significant drop of entropy values in the control group as compared with the entropy group which received a greater induction dose. Also, Rao et al., [14] found that SE \& RE were lower in the entropy group than control group at all readings except the baseline. The entropy values were $<65$ and $>50$ at induction, intubation and $1 \mathrm{~min}$ after in the control group. With intubation, SE \& RE increased in both groups but the RE-SE difference was $<10$. The difference may be due to: (I) Until intubation, SE was maintained <50, (Ii) Inclusion of younger patients. Also, Vakkuri A et al., [16] showed that all over the operation, in the entropy group, RE was higher (lower level of hypnosis) and propofol dose was lower. The difference with our results could be explained by use of cut-off value of RE 48 \pm 2 (Vs. 45-65 in their study).

\section{Conclusion:}

During intubation, usual titration of propofol until loss of verbal response, with the dose given in our study, is as good as entropy monitoring in elderly patients. So, routine use for this may not be necessary and can be used in other age groups, other anesthesia situations, medicolegal purposes and research.

\section{Recommendations:}

Further studies should be carried out to clarify the effect of use of entropy in dosage requirements of propofol used in induction of anesthesia in geriatric and should be performed on a larger sample size of patients and different type of surgeries for generalization of these results.

\section{Conflicts of interest: Nil.} role.

Authors' Contributions: All authors had equal

\section{References}

1- BRUHN J., MYLES P., SNEYD R. and STRUYS M.: Depth of anaesthesia monitoring: What's available, what's validated and what's next? Br. J. Anaesth., 97 (1): 85-94, 2006.

2- GOLPARVAR M. and TALAKOUB R.: Comparative evaluation of different values of bispectral index in determination of the appropriate level of anesthesia for tracheal intubation during inhalational induction of anesthesia in pediatrics. J. Res. Med. Sci., 16 (6): 770-5, 2011.

3- ADACHI Y.U., WATANABE K., HIGUCHI H. and SATOH T.: The determinants of propofol induction of anesthesia dose. Anesth. Analg., 92 (3): 656-61, 2001.

4- VIERTIÖ-OJA H., MAJA V., SÄRKELÄ M., TALJA P., TENKANEN N., TOLVANEN-LAAKSO H., et al.: Description of the EntropyTM algorithm as applied in the Datex-Ohmeda S/5TM Entropy Module. Acta. Anaesthesiol. Scand., 48 (2): 154-61, 2004.

5- AHO A., YLI-HANKALA A., LYYTIKÄINEN L-P. and JÄNTTI V.: Facial muscle activity, Response Entropy, and State Entropy indices during noxious stimuli in propofol-nitrous oxide or propofol-nitrous oxide-remifentanil anaesthesia without neuromuscular block. Br. J. Anaesth.,102 (2): 227-33, 2009.

6- VAKKURI A., YLI-HANKALA A., TALJA P., MUSTOLA S., TOLVANEN-LAAKSO H., SAMPSON T., et al.: Time-frequency balanced spectral entropy as a measure of anesthetic drug effect in central nervous system during sevoflurane, propofol, and thiopental anesthesia. Acta. Anaesthesiol. Scand, 48 (2): 145-53, 2004.

7- BONHOMME V. and HANS P.: Monitoring depth of anaesthesia: Is it worth the effort? Eur. J. Anaesthesiol., 21 (6): 423-8, 2004.

8- PRIEBE H.J.: The aged cardiovascular risk patient. Br. J. Anaesth., 85 (5): 763-78, 2000.

9- SCHULTZ A., GROUVEN U., ZANDER I., BEGER F., SIEDENBERG M. and SCHULTZ B.: Age-related effects in the EEG during propofol anaesthesia. Acta. Anaesthesiol. Scand., 48 (1): 27-34, 2004.

10- ARYA S., ASTHANA V. and SHARMA J.P.: Clinical vs. bispectral index-guided propofol induction of anesthesia: A comparative study. Saudi. J. Anaesth., 7 (1): 75-9, 2013.

11- RIAD W., SCHREIBER M. and SAEED A.: Monitoring with EEG entropy decreases propofol requirement and maintains cardiovascular stability during induction of anaesthesia in elderly patients. European Journal of Anaesthesiology, 24 (08): 684-8, 2007.

12- RUNDSHAGEN I., HARDT T., CORTINA K., PRAGST F., FRITZSCHE T. and SPIES C.: Narcotrend-assisted propofol/remifentanil anaesthesia vs clinical practice: Does it make a difference? Br. J. Anaesth., 99 (5): 68693, 2007.

13- RIAD W., SCHREIBER M. and SAEED A.: Monitoring with EEG entropy decreases propofol requirement and maintains cardiovascular stability during induction of anaesthesia in elderly patients. Eur. J. Anaesthesiol., 24 (08): 684-8, 2007.

14- RAO A.K., GURAJALA I. and GOPINATH R.: Comparison of electroencephalogram entropy versus loss of verbal response to determine the requirement of propofol for 
induction of general anaesthesia. Indian. J. Anaesth., 59 (6): 348-52, 2015.

15- GRUENEWALD M., ZHOU J., SCHLOEMERKEMPER N., MEYBOHM P., WEILER N., TONNER P., et al.: MEntropy guidance vs standard practice during propofolremifentanil anaesthesia: A randomised controlled trial. Anaesthesia., 62 (12): 1224-9, 2007.

16- VAKKURI A., YLI-HANKALA A., SANDIN R., MUSTOLA S., HØYMORK S., NYBLOM S., et al.: Spectral entropy monitoring is associated with reduced propofol use and faster emergence in propofol-nitrous oxide- alfentanil anesthesia. Anesthesiology, 103 (2): 274-9, 2005.

17- GÜRSES E., SUNGURTEKIN H., TOMATIR E. and DOGAN H.: Assessing propofol induction of anesthesia dose using bispectral index analysis. Anesth. Analg., 98 (1): 128-31, 2004.

18- LEE J.Y., CHOI S.R., CHUNG C.J., LEE J.H., PARK J.H. and BAIK C.Y.: The effect of spectral entropy monitoring on propofol use and recovery in children. Anesth. Pain. Med., 9 (2): 138-43, 2014.

\section{دراسة مقارتة بين الأنتروبى والأستجابة العملية لتحلديل

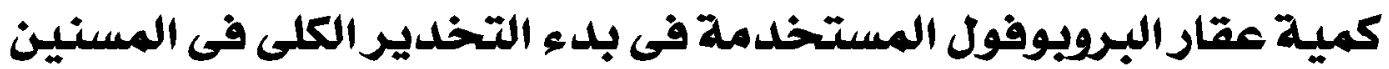

إن تركيب الأنبوبة الحنجرية واحد من أقوى المحفزات أثناء التخدير الكلى ويتم بعد الوصول إلى مستويات عميقة من التخدير. محاولة إدخال

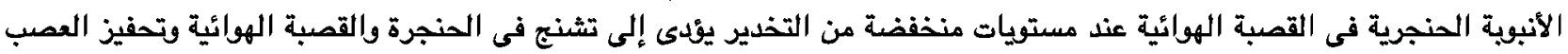

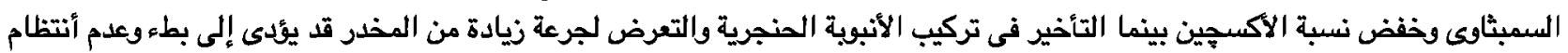

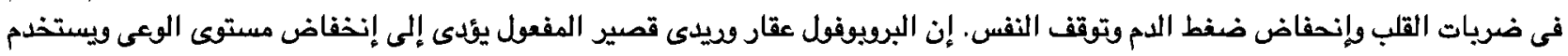

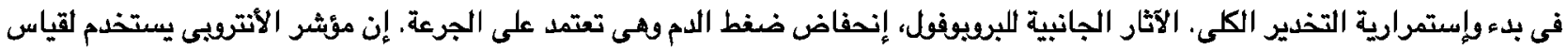

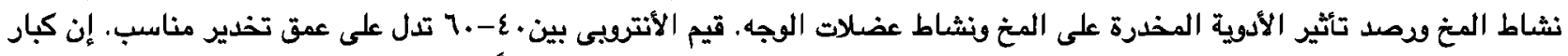

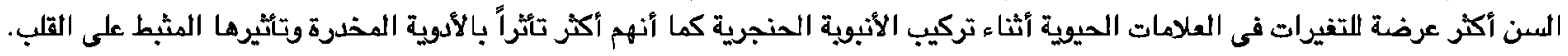

كان الهدف من الدراسة: المقارنة بين أستخدام الأنتروبى والطريقة التقليدية في التأثير على كمية البروبوفول المستخدمة في بدء التخدير

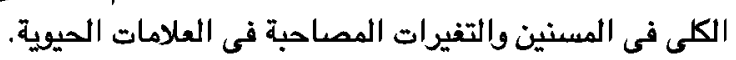

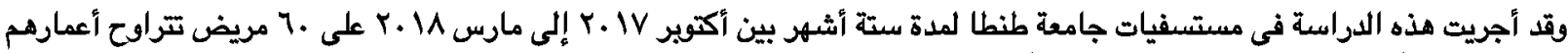

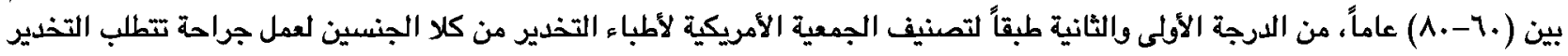

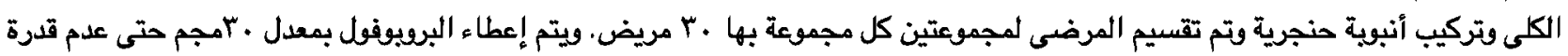

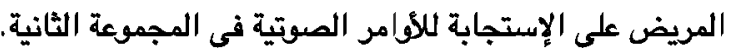

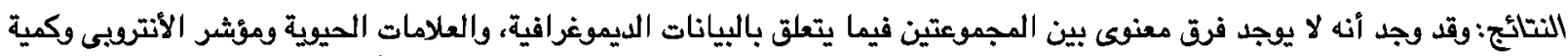

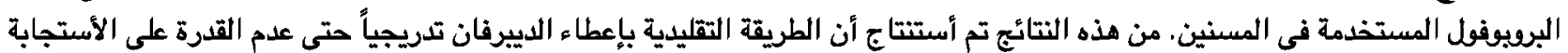
اللأوامر الصوتية لها نفس كفاءة الأنتروبى. 